Revista de Psicología Vol. 32 (2), 2014 (ISSN 0254-9247)

\title{
El Construccionismo Social como abordaje teórico para la comprensión del abuso sexual
}

\author{
Marlene Magnabosco Marra ${ }^{1}$ \\ University of Brasilia (UnB), Tel Aviv University (UTA)
}

\begin{abstract}
Este artículo se propone discutir el Construccionismo Social, como marco teórico para abordar el abuso sexual. Dicho marco favorece la construcción de nuevas narrativas, ofrece condiciones de reinterpretación de vivencias de abuso sexual, ayudando a las personas a ingresar en un relato más positivo de sus vidas y de su identidad. Al narrar historias de abuso sexual, las familias conocen y perciben otras y nuevas secuencias narrativas, hallando una pauta de sentido que corresponde al momento vivido. Estas conversaciones especiales incitan a la construcción de una nueva narrativa, invitando a la toma de una postura más reflexiva y crítica en relación con la violencia. Esta postura modifica la relación entre las personas involucradas en la conversación.

Palabras clave: construccionismo social, abuso sexual, significado, lenguaje, familia
\end{abstract}

\section{Social Constructionism as a theoretical approach to understand sexual abuse}

The text aims to discuss Social Constructionism as a theoretical approach for understanding sexual abuse. This approach enables the construction of new narratives, and creates conditions for the reinterpretation of the situations lived due to sexual abuse. It will furthermore help the person construct a more positive story of his/her life and identity. While narrating stories of sexual abuse, families get to know and perceive other new narrative sequences, finding a meaning that corresponds to the lived moment. These special conversations invite the reconstruction of a new narrative and enable a more reflective and critical position about violence. Additionally, there is a modification in the relation between the people involved in the conversation.

Key words: Social Constructionism, sexual abuse, meaning, language, family

1 Máster y doctoranda en Psicología Clínica y Cultura por la Universidad de Brasilia (UnB), Docente y coordinadora pedagógica del programa de Post Grado en Psicodrama y Terapia de parejas y Familia de la Pontificia Universidad Católica de Goiás (PUC GO) junto al Instituto de Investigación e Intervención Psicosocial (INTERPSI). Dirección postal SGAS 910, CONJ. B, BL. B, salas 223, 225, 227. Ed. Mix Park Sul. Asa Sul, Brasilia/DF, Brasil. 70390-100. Contacto: mmarra@terra.com.br 
El paradigma posmoderno abandona la dualidad entre el individuo y el mundo, y se desplaza hacia un encuadre sociolingüístico. Es un conjunto de pensamientos vinculados a la cultura que pone en relieve la realidad tejida en telares lingüísticos compartidos por todos. Además, enfatiza el carácter relacional e histórico de la construcción de la realidad como contexto de un proceso social, racional, histórico, lingüístico y cultural, subrayando el papel del lenguaje en el proceso de cambio terapéutico (Rasera \& Japur, 2005, 2007).

El discurso posmoderno implica necesariamente un posicionamiento crítico y una postura filosófica que propone: (a) una nueva visión de la persona y del mundo; (b) la convivencia con la inseguridad y la imprevisibilidad; (c) el rechazo de los discursos hegemónicos y mono vocálicos; (d) la presencia del sujeto cognoscente; (e) el lenguaje como un ícono del mundo real, proponiendo la coherencia y la viabilidad como valores epistémicos; (f) la invalidez de la interpretación esmerada de la realidad en la producción del conocimiento; y (g) el conocimiento comprendido como una práctica discursiva socialmente construida, con múltiples narrativas, considerando múltiples posibilidades y versiones (Anderson, 1990; Foucault, 1978; Gergen, 1985, 1996, 1999, 2006; Grandesso, 2000; Ibañez,1992).

El Construccionismo Social es un abordaje, representante auténtico del pensamiento posmoderno. El pensamiento de la posmodernidad se configura como un paraguas paradigmático (Grandesso, 2008), que se manifiesta en un conjunto de principios y derivaciones prácticas organizadas por los enfoques constructivistas y construccionista social. El Construccionismo reúne un conjunto de contribuciones teóricas (teorías, narrativas, prácticas colaborativas y procesos reflexivos) que han contribuido principalmente con la psicología social, y más recientemente surgen como aporte a la psicoterapia en general. Los críticos posmodernos valorizan las conexiones entre las personas y se basan en 
la creencia de que las interpretaciones y las intervenciones no ocurren a menudo, y que confirmar el significado de las personas es el punto alto de dicha propuesta (Anderson, 1990; Gergen, 1985, 1996, 1999, 2006; Grandesso, 2000; Rasera \& Japur, 2005, 2007).

Estos pensadores también sostienen que los terapeutas parten del "no saber" y rechazan la idea de buscar problemas y enfermedades en sus tratamientos clínicos. No existe conocimiento definitivo y útil que se pueda generalizar, ni tampoco situaciones que definan la esencia última de la persona. El foco está en el lenguaje que construye esos mundos sociales. La vida de las personas se organiza por el significado construido acerca de sus experiencias y se atribuye a esas conexiones. De este modo, el significado de cualquier vivencia dependerá del contexto, y los recursos para esa significación no siempre se hallarán en la persona misma, sino en sus relaciones. Dichos recursos son metáforas, significados, discursos y representaciones que constituyen tanto conocimientos como experiencias que son consideradas y legitimadas en los contextos de conversación (Anderson, 2010; Epston, 1997; Gergen, 1985; Grandesso, 2002, 2008; Hoffman, 1993, 2001; White \& Epston, 1993).

Este presente artículo se propone entender de qué modo el Construccionismo Social como base teórica introduce la posibilidad de la construcción de nuevas narrativas y, en consecuencia, ayuda a las familias a comprender sus vivencias de violencia y abuso sexual. Al narrar historias de abuso sexual, las familias conocen y perciben diferentes y nuevas secuencias narrativas, encontrando una pauta de sentido que corresponde al momento vivido. Las familias ingresan de esta forma en un relato más positivo de su vida y de su identidad personal y social, y comienzan a distinguir entre experiencias y acciones de índole amorosa que expresan cuidados mutuos, de aquellas acciones que constituyen el abuso y la explotación sexual.

Los estudios sobre las familias donde existe el abuso sexual han sido especialmente relevantes para el conocimiento de prácticas que contribuyen tanto para prevenir, como para el conocimiento y tratamiento del fenómeno. Las víctimas y sus familias necesitan manifestar sus percepciones, lo que saben o no a respecto de lo que están viviendo, 
e interpretar esas vivencias y narrar sus historias de abuso. Sin embargo, los trabajos existentes demuestran de modo general que las intervenciones que no les brindan a las víctimas oportunidades para que estas se expresen y que se limitan a la presentación objetiva de las informaciones acerca del abuso (Habigzang \& Caminha, 2004; Santos, Pelisoli \& Dell' Aglio, 2012), no modifican las vivencias de los involucrados y tampoco agregan nuevos significados al proceso.

Conforme a lo expuesto, este texto busca comprender qué es el Construccionismo Social y sus implicaciones como un proceso de auto reflexión, organizado alrededor de los conceptos de construcción mutua, tanto de los problemas como de las soluciones. Este abordaje es considerado un espacio ideal para que la familia exponga sus narrativas, explorando nuevos significados y sentidos sobre lo que viven, ya que es en los contextos relacionales que las personas construyen sus comprensiones sobre la realidad que las rodea y sobre sí mismas, organizando nuevas construcciones y nuevos arreglos lingüísticos. Al explorar un nuevo enfoque narrativo para sus vivencias de violencia, se posibilita el surgimiento de relatos alternativos que ayudan en la comprensión de esas vivencias y en la promoción del auto respeto.

\section{El Construccionismo Social: concepto y breve historia}

El construccionismo social surge en medio de un conjunto complejo de propuestas teóricas de las ciencias humanas en la contemporaneidad. Este abordaje se constituye como movimiento de crítica a la psicología social "modernista" y se fundamenta principalmente a partir de Kenneth Gergen. El pensamiento posmoderno y las ideas construccionistas sociales se aplican a las prácticas terapéuticas, psicosociales, en la enseñanza, en el consultorio y en la organización (Gergen, 1996; Gergen \& Gergen, 2010; Shotter \& Lannamann, 2002).

La postura posmoderna que acompańa los cambios paradigmáticos en los fines del siglo XX se caracteriza por ser generadora y creadora de una nueva comprensión y direccionalidad. La principal cuestión que 
señalan varios teóricos (Anderson, 1990, 2010; Gergen, 1985, 1996, 1999, 2006; Grandesso, 2000, 2002, 2008; Omer, 1997, 2011; Rasera \& Japur, 2005, 2007; Shotter, 1993a; White \& Epston, 1993; White, 1994, 2002) es la metáfora del aprender hablando la lengua de quienes están siendo escuchados. La máxima de esa postura es "escuchar para comprender”. De esta manera, se postula una posición de construcción mutua de un conocimiento significativo para los involucrados en la acción, en donde el sentido de autoría y la importancia de las formas especiales introducidas en los diálogos y los procesos son más significativo que los resultados. El lenguaje y el conocimiento son entidades dinámicas, en constante construcción y reinterpretación. El énfasis está puesto en la trilogía: hermenéutica contemporánea, construcción social y teoría narrativa. Estas ofrecen subsidios para la organización de las experiencias vividas y la evolución del sistema terapéutico, destacando los sistemas lingüísticos, las narrativas, la conversación, el diálogo, las historias, el significado y la cultura. De esta forma, se construyen no solo los cambios, sino también el individuo y su contexto, así como un discurso de potencialidades y de construcción de realidades futuras.

Los sistemas lingüísticos, organizados entre transacciones de protagonistas y negociados entre las redes conceptuales de las personas, confirman distintas formas de estar en el mundo, mientras rechazan o evitan otras. Asimismo, estos sistemas posibilitan que determinadas descripciones del sí mismo se modelen, creando un camino de reflexión hacia un conocimiento especialmente activo, construido en vez de ser descubierto. Ese sendero epistémico se considera una práctica crítica de lo social y de lo sociocultural, ordinario y cotidiano; y se constituye como una micropolítica, que opera, negocia y regula un poder constitutivo que busca el no ejercicio opresivo de un grupo privilegiado sobre los demás. Asimismo, esta práctica es una experiencia sociocultural positiva, formadora y no restrictiva o represiva. Es una construcción de sentidos con propuestas de nuevas metáforas y discursos alternativos para la descripción de lo vivido (Grandesso, 2002; Pakman, 2011; Rasera \& Japur, 2007). 
El Construccionismo Social nació y se estableció en el campo académico norteamericano, comenzando en la década de 1970, cuando el Conductismo y sus presupuestos ontológicos y metodológicos se veían cuestionados. Gergen en 1973 fue uno de los cuestionadores con su crítica historicista a la psicología social en sus obras Social Psychology as History (1973) y The Social Constructionist Movement in Modern Psychology (1985), las cuales se han constituido como los marcos iniciales del Construccionismo Social. El autor considera que el esfuerzo para construir leyes generales para el comportamiento social es equivocado y adopta una postura relativista. De esta forma, define al construccionismo social como un movimiento, un intento de disolver el objeto tradicional de la psicología, sustituyendo la realidad de la mente y del comportamiento, por convenciones y recursos lingüísticos con una reflexión histórica y contextual como centro de la actividad en la psicología. Para Gergen (1985, p. 266) "el construccionismo social concibe el discurso sobre el mundo no como un reflejo o un mapa del mundo, sino como un producto de la interacción social".

El Construccionismo Social se considera un movimiento que apunta a la discusión de una ética y una política relacional, existente en el grupo familiar y en los demás grupos. Su dimensión ética enfatiza la importancia de las relaciones sociales como espacio de construcción del mundo. La realidad es siempre representada a partir de un punto de vista cultural y un lenguaje particular. Aunque la realidad de la palabra, como es el caso de cualquier signo, resida entre individuos, la palabra, al mismo tiempo, se produce por medio del mismo organismo específico, sin cualquier recurso, cualquier equipamiento o cualquier otro tipo de material extracorpóreo (Shotter \& Lannamann, 2002).

$\mathrm{Al}$ referirse a las principales características epistemológicas y ontológicas del Construccionismo Social, Gergen (1999) apunta cuatro cuestiones esenciales: (i) conocer el mundo por la historia y por la cultura; (ii) tener en cuenta la interacción entre las personas; (iii) la relación entre conocimiento y acción; y (iv) el realce de una postura crítica y reflexiva como producción del conocimiento. Se percibe entonces que este abordaje cuestiona realidades y valores de la vida cotidiana, e 
implica descubrir la estructura interna de los significados, construyendo significados compartidos. No hay verdades para verificar, sino significados relevantes para cada persona, lo que confirma que la búsqueda de la verdad se basa en la diversidad de sus manifestaciones y nunca se revela en su totalidad. Por lo tanto, es necesario que se problematice el fenómeno revelado para que sea mejor comprendido.

\section{Las narrativas y los significados}

Las personas viven de acuerdo a las historias que construyen sobre la experiencia vivida. Cuando cuentan sus historias, son protagonistas y entienden mejor sus vidas, las alegrías y los sufrimientos por los cuales transcurren. Todas las vivencias solo tienen sentido porque poseen una historia. Ser el personaje principal significa ser el autor de su propia vida. Los terapeutas construccionistas creen que la persona al narrar un evento de su vida, reescribe su historia. De ahí que los problemas puedan resolverse y/o transformarse, creándose nuevas historias, mientras que nuevas oportunidades ganan visibilidad. Recrear espacios ya vividos y momentos valientemente enfrentados, permite abrir nuevos campos y direcciones.

Las narrativas son eventos ligados en secuencia a través del tiempo de acuerdo con un enredo. White y Epston (1993) están comprometidos con este campo del conocimiento en terapia familiar. Esos autores destacan que los relatos no nacen de la "nada", sino se construyen a partir de una red de procesos integrados por múltiples eventos de manera recursiva. La interacción de diferentes prácticas es construida y construye las situaciones de la vida cotidiana. No existe una definición precisa sobre qué son las narrativas, pero se pueden comprender como formas lingüísticas usadas para contar algo sobre el proceso vivencial y para expresar experiencias y situaciones.

Las narrativas son construcciones complejas alrededor de tramas temáticas, construidas en una dimensión histórica y negociadas socialmente, manteniéndose siempre abiertas a la reconstrucción, y 
no constituyéndose como una posesión de las personas, sino de sus relaciones vividas en un sistema social e histórico, y en los modos discursivos reservados por la cultura. Por lo tanto, no se refieren solamente al mundo interno de la persona o a sus cogniciones, sino también son formas sociales de significar lo ocurrido, y organizar las acciones que forman parte del proceso conversacional (Gergen, 1996).

Las narrativas organizan y definen significados y sentidos de las experiencias de las personas, siendo "instrumentos incrustados en las secuencias conversacionales" (Gergen, 1996, p. 234), además de recursos culturales que cumplen un propósito social. Una vez comprendidas como instrumentos y recursos, se puede concluir que, al narrar una experiencia, se están construyendo relatos y expresiones de la misma, promocionando cambios y transformaciones en las vivencias.

Los textos o tramas se estructuran a partir de construcciones lingüísticas y permiten la formulación de relatos conformados por secuencias, que se ordenan en enunciados, argumentos y descripciones. Estos relatos se encuentran ligados de forma imprevisible con otros procesos y/o eventos presentes en la interacción entre las personas, estableciendo maneras de percibir las experiencias del sí mismo y de otros sistemas (Gergen, 2006; Rasera, Guanes \& Japur, 2004; White \& Epston, 1993).

Para Gergen (1999) la atribución de significado parte de cambios dialógicos, base para las prácticas narrativas, ya que son procesos sociales dialógicos. Los dilemas humanos son los significados estructurados de narrativas. Etimológicamente, significado en latín es significátus, significáre, es decir, dar a entender por signos, indicar, mostrar, significar, dar a conocer, hacer comprender. Por lo tanto, el significado de los sucesos vividos se construye en el lenguaje y se captura por medio de las narrativas. Lo que se enfatiza o se omite de las historias contadas tienen efectos reales sobre las vidas. La forma de atribuir significados a los eventos afecta la manera cómo se construye la identidad, o cómo una persona actúa en relación a sus contextos y a los otros. Se depende del lenguaje para generar las propias narrativas, dar sentido a los significados, a la existencia. Se interpreta el mundo y todo lo que en él existe 
por el lenguaje que surge en el dominio social, a partir de las vivencias cotidianas.

Dado que el Construccionismo Social es considerado una manera de estar en el mundo, como generación mutua del conocimiento que se construye en el lenguaje y en el relacionamiento, se puede afirmar que tanto la postura colaborativa como el diálogo son aspectos fundamentales para el acercamiento de los significados y la construcción de nuevas narrativas para las vivencias. Muchas historias son vividas simultáneamente, existiendo diferentes historias sobre los mismos eventos. Ninguna de ellas está libre de lagunas, ambigüedades y contradicciones. Esas historias postulan un desarrollo ubicado sociohistóricamente, que da relevancia al contexto sociolingüístico, y hace hincapié en la narrativa o forma de relato del significado. Son las historias y los diálogos que posibilitan revisar y evaluar los argumentos de lo vivido, como los atribuidos a los episodios de abuso sexual en las familias (White, 1994, 2002; Shotter, 1993b; Rasera et al., 2004).

Estos individuos buscan, junto con aquellos que han sufrido violencia sexual, un cambio de perspectiva para sus vidas, a través de la deconstrucción de sus motivos justificantes ante las conductas abusivas, con el objetivo de elaborar nuevas y potenciales narrativas del futuro. Asimismo, los argumentos inspiran la apreciación de un mundo plural y diverso con una multiplicidad de prácticas en el que todos recíprocamente se transforman, con perspectivas de nuevas formas de vida que favorezcan una mejor convivencia (Castañon, 2004; Gergen, 1996, 2006; Rasera \& Japur, 2007).

\section{El lugar del abuso sexual: una conexión con las historias dominantes}

Diferenciadas formas de violaciones de los derechos y abusos sexuales de niños y adolescentes son consecuencias de los grandes cambios sociales y tecnológicos, entre otras influencias como los factores económicos y culturales en la actualidad. La cotidianidad, marcada por la violencia, degrada y descalifica la relación entre las personas. El abuso 
sexual es una violencia que tiene que interrumpirse, pero para ello es necesario que se le vede urgentemente, tal como señala Faleiros (2008). Aunque con el cambio de comprensión acerca de lo que es un niño o un adolescente en el siglo XXI, considerados sujetos de derechos, aún así, la complejidad de esa cuestión está presente en la vida cotidiana. Los/as niños/as y adolescentes se desarrollan en ambientes sociohistóricos complejos, formados por diversos sistemas que influyen y son influenciados por ellos.

El abuso sexual es un fenómeno determinado por diversos factores, el cual abarca aspectos culturales, socioeconómicos, individuales y familiares. La relación sexual es un tipo particular de relación social implicando límites individuales y sociales. En la situación de abuso sexual, la víctima es tratada como objeto parcial, o incluso como objeto inanimado (fetiche), de manera que la persona no es respetada en su decisión y autonomía. Aunque el hecho ocurra sin violencia o sin marcas físicas evidentes, sí se considera un abuso sexual, dado que el/la niño/a y el/la adolescente están supeditados a una fragilidad física y emocional ante el otro (Azevedo \& Guerra, 1989; Cardin, Mochi \& Bannach, 2011; Cohen, 2000; Cohen \& Figaro, 1996; Esber, 2009; Habigzang, Koller, Azevedo \& Machado, 2005; Penso, Conceição, Costa \& Carreteiro, 2011; Santos, Costa \& Granjeiro, 2009).

El abuso sexual incluye las actividades en las que hay contacto físico, la manipulación de genitales y el acto sexual, así como situaciones de exhibicionismo y voyerismo, en los que no hay contacto físico directo. Generalmente el/la niño/a y el/la adolescente, víctimas de abuso sexual, experimentan también negligencia, abuso emocional y abuso físico. Otras definiciones incluyen actos y juegos sexuales, relaciones heterosexuales u homosexuales, observándose que el/la abusador/a siempre tiene más edad que el/la abusado/a. Estos actos producen la violación de las reglas de funcionamiento social y legal, muchas veces bajo el consentimiento u omisión de personas que forman parte y son importantes en la vida de los/las niños y de los/las adolescentes. Las víctimas son seducidas e involucradas en acciones que les suenan agradables, y que además son coherentes con el afecto que 
le brinda la persona abusadora. Empiezan con formas bastante sutiles, involucrando gradualmente a la víctima en situaciones abusivas hasta llegar a las prácticas más violentas. Son formas que varían desde un simple cariño y expresión de afecto, la exhibición de películas pornográficas, hasta un contacto con acto sexual completo, independiente de la edad del niño o de la niña (Azevedo \& Guerra, 1989; Costa, Almeida, Ribeiro \& Penso, 2009; Furniss, 2002; Habgzang, Damásio \& Koller, 2013, Habigzang, Hatzenberg, Corte, Stroeher \& Koller, 2009; Leal \& Cesar, 2007; Sanderson, 2005).

Sanderson (2005) afirma que no son las familias las que abusan a los/as niños y adolescentes, sino los individuos. Este fenómeno puede ocurrir en cualquier familia, no solamente en aquellas consideradas pobres, vulnerables, de riesgo, desestructuradas y/o disfuncionales. De esta forma, se entiende que el abuso sexual se debe caracterizar por situar cada caso en particular, considerando que difícilmente se abracarán todas sus circunstancias, ya que existe una diversidad de individuos, acciones y los contenidos de la sexualidad impuestos a las víctimas. El sufrimiento humano respecto a estas cuestiones es, muchas veces, enmudecido, banalizado y tolerado en todas las esferas sociales, dificultando una acción más consciente y modificadora de la realidad. Asimismo es importante incluir las numerosas historias de sufrimiento que se han vivido en silencio, en la invisibilidad social, debido a la demora del tratamiento por parte de los servicios públicos y/o la no notificación de la situación a los servicios especializados (Santos, Costa \& Silva, 2011).

Cuando el/la nińo/a o adolescente se reúne con una persona de confianza — generalmente la madre - para hablar de la situación tras el abuso ocurrido, este encuentro deja una huella registrada, es decir, el sentido como indicador de la existencia de problemas que involucran todo el sistema familiar. Esos sentidos se unen a las narrativas cristalizadas, rótulos e historias dominantes del interlocutor, debilitando aún más el vínculo existente entre la víctima y su interlocutor, y reforzando los discursos culturales que los mantienen.

Esa marca, indicador del significado, al expresarse en esa conversación, constituye un texto, que es en sí una construcción lingüística. 
Ese texto, construido mutuamente con sus interlocutores, expresa sus pensamientos, sentimientos e impresiones acerca de las cuestiones de abuso. Ese intercambio de unidades de sentido puede transformar esa reunión en un encuentro fomentador de posibilidades, o no. Por ejemplo, muchas veces la persona que oye el relato del nińo puede no creer en dicho relato. Esas personas, que pueden ser vistas como no protectoras, detentoras de creencias y mitos, por sus comportamientos hostiles a cualquier mención de abuso sexual, poco o nada ayudarán a aquel niño a salir de ese discurso y a buscar formas alternativas de encontrarse con sus posibilidades (White, 2002; Shotter, 1993a).

Muchas veces al interlocutor que oye esos relatos le parece difícil dar un nuevo sentido a un suceso que contradice el relato dominante. Por ello, responde exactamente al relato dominante, no permitiéndose observar hacia su interior y verificar si es posible plantear un relato alternativo que lo ayude a salir de aquella situación que lo aprisiona. El interlocutor tiene dificultades para ejercitar su toma de consciencia para expandir y articular sus posibilidades. No saben por qué actúan de la manera en que actúan. Sin embargo, al encontrarse con sus mapas y territorios ya vividos, pero poco o nada narrados e historiados, van a darse cuenta de sus experiencias de abuso sufridas en la nińez. Narrar experiencias y contar historias puede ser curativo, porque es una forma de volver a visitar el sufrimiento, y poder transformar un discurso negativo en otras historias, con innovadoras ediciones y con oportunidades alternativas de un nuevo comienzo (White, 2002; White \& Epston, 1993).

Los discursos dominantes se han construido con la ausencia de creer en el relato del/de la niño/a. Para esos códigos, los/las niños/as mienten y los/las adultos dicen la verdad, o las comunicaciones de los/las niños/as son menos válidas o menos fiables que las de los/las adultos (White, 2002). En función a esa situación, los/as niños/as casi siempre están obligados a convivir con la persona que cometió el abuso y a seguir siendo abusada sexualmente. El/la niño/a aprende ese discurso dominante muy temprano, lo introduce en su vida, silencia el abuso sexual, y luego cuando se llega a la adultez ve la misma situación ocurriendo en sus hijos, que corresponde a una transmisión 
transgeneracional de la violencia (Penso \& Costa, 2008). A sabiendas de estas situaciones, el/la niño/a que a menudo sufre abuso, está obligado/a a no revelar lo que está viviendo. Este proceso continuo por mucho tiempo se transforma en un secreto entre él y el adulto, el cual es siempre reforzado por las amenazas de violencia o castigos, o por ganancias secundarias y privilegios que igualmente se basan en la violencia. Esta situación es siempre un conflicto y un trastorno dañino para el/la niño/a (Azambuja, 2006; Borges \& Dell' Aglio, 2008; Furniss, 2002; Leal \& Cesar, 2007; Lippert, Favre, Alexander \& Cross, 2008). Muchos de esos/as niños/as nunca han contado sus historias o han narrado sus emociones y sentimientos vividos, destruyendo y no apreciando su trayectoria de vida. De esa forma, se crean textos para comunicar sus dolores y amarguras en las relaciones con los otros.

\section{El Construccionismo Social como propuesta para la comprensión del abuso sexual}

El modo que utilizan las familias para expresar sus sufrimientos sobre las experiencias de abuso sexual vividas es moldeado por los significados atribuidos al abuso sexual. La forma de expresión confirma el significado, de tal manera que al analizarse la naturaleza de las expresiones de abuso, estas se deben considerar como unidades de sentido, es decir, como un texto. Texto es un conjunto de palabras con autoría identificada, con forma y contenido original, con una finalidad discursiva que produce efecto sobre las personas involucradas y demás individuos que participan a la red discursiva. Según Bakhtin (1952-1953, citado en Ponzio, 2010) el texto tiene tres dimensiones: producto, proceso y productor. El texto comprende un enunciado único y particular, es visto como una unidad básica de comunicación y posibilita la construcción de sentidos sobre la realidad, constituyéndose en un contexto dinámico de la relación social delimitada por un espacio histórico-cultural.

Así, para cada nuevo texto se percibe un reposicionamiento de los interlocutores del diálogo, es decir, una cadena discursiva. Esa cadena es 
una unidad de sentido que igualmente responde a enunciados anteriores y asimilados en su trayectoria de vida. Bakhtin (1952-1953, citado por Ponzio, 2010, p. 56) señala que "cada enunciado es un enlace en la corriente compleja organizada de otros enunciados". Esta cita intenta expresar que la verdad no se encuentra en la cabeza de uno, sino que nace en medio de las personas que de manera colectiva la buscan en el proceso de su interacción dialógica. Un acto de pensamiento, de sentimiento o de deseo siempre es un acto de autoría propia. El lenguaje se ha desarrollado históricamente para servir al pensamiento participante y solo recientemente ha empezado a servir al pensamiento abstracto. En todos los momentos, sea de la palabra concepto o de la palabra entonación, esta es plena, única, y responsablemente significativa. Puede ser la verdad privada, subjetiva y fortuita. El existir, evento irrepetible y singular, además del acto del que participa, no define la plena adecuación, aunque ella permanezca como un fin. Por lo tanto, texto es un conjunto de palabras con autoría identificada, con forma, contenido original y con finalidad discursiva, que produce un efecto sobre las personas y sobre los demás que participan de la red discursiva.

Según Bakhtin (1952-1953, citado por Ponzio, 2010), el existir de un evento real, que se vive y se proyecta en tonos emotivos-volitivos, tiene una correspondencia con un centro único de responsabilidad, y se determina en su sentido de evento singular grave, necesario, en la verdad privada, no en sí mismo, sino en correspondencia directa con la singularidad de cada uno. El evento, necesariamente, es determinado por cada uno, desde su lugar de existencia. Así, cada uno tiene razón en su propio lugar, no como una razón subjetiva, pero responsable.

Es sabido que las soluciones se encuentran mutuamente cuando se presta atención al texto y al interlocutor, siendo el punto de vista narrativo inclusivo. A medida que la persona narra sus historias compuestas de sentimientos, sensaciones y argumentos, avanza con articulaciones y experiencias sobre otras maneras de ser y de pensar, con valores, compromisos y creencias para arribar relatos alternativos de vida. La postura inclusiva del Construccionismo Social posibilita a aquel que acompaña al sujeto a mostrarse interesado en saber cómo ha sido la vida 
para esas personas, sus relatos y experiencias, explorando con ellas sus experiencias del problema, en una conversación colaborativa (Anderson, 2010; White, 2002). Esta propuesta del Construccionismo Social envuelve, desde su inicio, la creación de un espacio confortable y confiable, a fin de que la familia no se convierta en un objeto del cual se habla y sobre el cual se interviene, pero en un espacio de conversación en el que se pueda hablar sobre dificultades, problemas y revelaciones, sin convertirlos en definidores de la identidad de aquel que habla. Por lo tanto, la madre y el niño que se presentan para hablar de la violencia sufrida en el abuso sexual, son colocados en la condición de agentes dentro del proceso de conversación, y a ellos se consideran colaboradores activos para generar alternativas de cambio. Todo ello es darle asistencia a la madre y al niño/a en la producción de conocimiento, generando sus propias soluciones (Grandesso, 2002; Epston, 1997).

Generalmente la madre y el/la niño/a son los protagonistas de la conversación, trayendo sus historias sobre los problemas que involucran violencia, habiendo una narrativa dominante que organiza la relación entre los dos. Esas narrativas dominantes dirigen la atención de la madre y, consecuentemente, del/de la niño/a, para determinadas situaciones y para la pérdida de informaciones que no encajan con las historias dominantes. Por otro lado, las informaciones que confirman y que comprueban las suposiciones fijas de las madres, presentan una lógica constitutiva de su dilema de modo invariante y sin perspectiva de cambio. Por tanto, las narrativas saturadas de problemas ejercen influencia selectiva sobre las percepciones, disminuyendo las posibilidades de futuro (Grandesso, 2002; White \& Epston, 1990).

La desconstrucción de la historia dominante va a ocurrir a través del rescate de la eventualidad de los contextos y de la apertura de las historias para episodios vividos, pero no historiados todavía. El Construccionismo Social valoriza la palabra que da significado a los eventos vividos, la producción de sentido, a través de la conversación que promueve la reflexión y la crítica (White 1994, 2002; White \& Epston, 1993). En el abuso sexual hay violencia, pero no siempre hay el reconocimiento de esa violencia, pues es necesaria la atribución de 
significados a la violencia y a su sentido en la percepción del abuso sexual. Por ende, ese abordaje ayuda en la concientización del abuso sexual y en la reconstrucción del sentido de cómo observar un panorama diferente y de cómo volver a la vida después de sufrir esa violencia.

Se trata de conversaciones que incitan la reconstrucción de una nueva narrativa, que invitan a la toma de una postura más reflexiva y crítica con respecto a la violencia, favoreciendo la creación de un contexto lingüístico, y permitiendo a su vez que todos hablen de sus experiencias. Esa postura reflexiva modifica la relación entre los involucrados en la conversación, principalmente entre la madre y la víctima. La conversación potencializa la madre y le da autorización para hablar, además de poner en relieve las historias que marcan sus mismas vivencias de violencia, generalmente de abuso sexual en su niñez. Además, le da la oportunidad de relatar lo que nunca antes había sido relatado acerca de esos eventos abusivos. La madre halla en este contexto colaborativo un espacio en el cual puede de-construir sus antiguas historias, aún actuales, expresadas en la vivencia de la hija o del hijo (Costa et. al., 2009; Penso \& Costa, 2008; Grandesso, 2000).

Es en este momento en que la perspectiva de comprensión ocurre, la relación entre ellos se transforma, modificando la narrativa. La mujer, o madre allí presente, se vuelve un asociado calificado de la conversación, una efectiva "acción conjunta", un entendimiento caracterizado como una especie de conocimiento que nace desde dentro (Shotter, 1993b), denominado por este autor como un conocimiento de tercer tipo. La madre, al darse cuenta de sus experiencias, se torna una colaboradora activa en el proceso de reconstrucción de nuevas narrativas. La narrativa emergente que surge de ese espacio colaborativo, a diferencia de la narrativa dominante saturada de problemas, se organiza como propuesta para lo nuevo, resignificando las personas como autoras de su existencia e invitándolas al rescate de sus recursos de enfrentamiento de la vida. La narrativa emergente crea una historia alternativa, que desarrolla un sentido de protagonismo. Esa reconstrucción, considerada un juego conversacional, está dirigida a delinear los efectos de esa violencia en la vida, en las relaciones, en la visión de sí mismo y en 
sus expectativas de futuro. Ese espacio de conversación posibilita un lenguaje compartido y pleno de metáforas, signos y sentidos que favorecen la reconstrucción lingüística por considerar cuestiones de género, extracto social, cultura y etnias (Carrijo \& Rasera, 2010; Gergen, 1985; Grandesso, 2008). El Construccionismo Social está interesado en desentrañar cómo las personas determinan las maneras preferibles de vivir, de interactuar consigo mismas y con los demás. Si lo que viven, y la manera en que viven, no es bueno para los individuos, es posible explorar otras maneras de vivir y de pensar, trayendo a tono un reservatorio de historias acerca de cómo podrían vivir mejor, liberarse de los relatos negativos y dominantes que tienen sobre sí mismos, poniendo en práctica lo que los significados alternativos posibilitan (White, 2002).

Los eventos humanos solo se vuelven inteligibles tras haber sido historiados. Por medio de las conversaciones se forma y se reforma la experiencia de vida y los eventos relacionados con los sufrimientos. Se crean y se recrean los significados y las comprensiones, las construcciones y las reconstrucciones de las realidades y del self. Se interpretan y se reinterpretan activamente las experiencias a lo largo de la vida, y esto ocurre debido a que se accede a algunos marcos de inteligibilidad que sitúan en un contexto a la experiencia, posibilitando la atribución de nuevos significados (Hoffman, 1993; White, 2002).

\section{Consideraciones generales}

Actualmente la violencia sexual es vista como un fenómeno social de orden colectivo, como una construcción social, organizada a partir de valores culturales y sociales, referidos a pensamientos de jerarquía, poder, género y extracto social, e influida por significados que incluyen los aspectos de los fenómenos intrapsíquicos. Las dificultades, los problemas, y las situaciones traumáticas vividas evolucionan con los sistemas culturales y con los de significado personal. Se hallan incrustadas en los comportamientos y en las acciones, los cuales influyen en la manera de como uno es, como actúa en el mundo, y como cada uno 
se ve a sí mismo y a los otros. Por ello, al relatar una historia, son los significados los que le confieren sentido a las experiencias y seleccionan los aspectos a los cuales se les dará más importancia, originando contextos de interacción que sostienen, o no, lo que se privilegia (Costa et al., 2009; Gergen, 1999; Grandesso, 2008).

Las experiencias de abuso sexual vividas por los/as niños/as y adolescentes en sus familias siempre son privadas, pero los significados son compartidos, por lo que se tornan públicos. El compartir el secreto con la familia tiene como reto convertir las relaciones entre sus miembros en relaciones más claras y transparentes, además de posibilitar el descubrimiento de aspectos confusos y contradictorios presentes y expresados en las emociones. Al reinterpretar las narrativas de esas vivencias, la familia busca nuevos significados, rescatando su rol de protección.

El Construccionismo Social posibilita no una verdad absoluta, pero motiva a crear diálogos en la interacción con los demás. De esta forma, pensar en nuevos puntos de vista, en una nueva manera de hablar de las mismas cosas, en un medio heurístico para resolver las dificultades. Esta perspectiva construccionista se puede identificar en las situaciones de abuso discutidas en este texto. Las interpretaciones y reinterpretaciones que las personas hacen del abuso vivido van a depender de sus historias de vida, pues en las culturas se tienen diferentes sentidos para esas cuestiones, tales como la dificultad para distinguir abuso de la protección, el abandono del cuidado, la explotación de amor. Se sabe entonces que las personas que han sufrido abuso son o están sumamente vulnerables. Es preciso seńalar que la perspectiva construccionista social proporciona un contexto adecuado para ayudar a las personas a hacer este discernimiento, contribuyendo a que se embarquen en conversaciones que establezcan distinciones entre estas clases de expresión e interpretación, para identificar buenos y eficaces eventos en su vida, encontrándose en territorios que sean de cuidado consigo mismo y con su capacidad resiliente. Al narrar sobre los pasos que han experimentado en el trascurso de su historia de abuso sexual, empiezan a cuestionar los modos de vida que se les han sido enseńados y cómo podrían hacerlo de otra manera, encontrando fuerzas que podrán utilizar para reorganizar su vida. 
Para los construccionistas, las personas que han sufrido abuso sexual como una experiencia violenta, intrusiva y angustiante, informarse nuevamente sobre los hechos produce nuevas vivencias opresivas y abusivas. Sin embargo, narrar las historias implica en la mayoría de los casos el desarrollo de una nueva autopercepción, basada en ideas de competencia, elaborando y fortaleciendo sentimientos y experiencias y una nueva corajosamente versión de sí mismo.

\section{Referencias}

Anderson, H. (1990). Then and now: From knowing to not-knowing. Contemporary Family Therapy Journal, 12, 193-198.

Anderson, H. (2010). Conversação, Linguagem e possibilidades. Um enfoque pós-moderno da terapia. São Paulo: Editora Roca.

Azambuja, M. R. F. (2006). Violência sexual intrafamiliar: é possível proteger a criança? Revista Virtual Textos \& Contextos, 5, 1-19.

Azevedo, M. A. \& Guerra, V. N. A. (1989). Crianças vitimizadas: a sindrome do pequeno polegar. SãoPaulo: IGLU.

Borges, J. L. \& Dell'Aglio, D. D. (2008). Relaçôes entre abuso sexual na infância, transtorno de estresse pós-traumático (TEPT) e prejuízos cognitivos. Psicologia em Estudo, 13(2), 371-379.

Cardin, V. S. G., Mochi, T. G. \& Bannach, R. (2011). Do abuso sexual intrafamiliar: uma violaçáa aos direitos da personalidade da criança e do adolescente. Revista jurídica Cesumar, 11(2), 401432.

Carrijo, R. \& Rasera, E. F. (2010). Mudanças em psicologia de grupo: reflexão a partir da terapia narrativa. Psicologia Clínica, 22(1), 125-140.

Castañon, G. A. (2004). Construcionismo social: Uma crítica epistemológica. Temas em Psicologia da SPB, 12(1), 67-81.

Cohen, C. \& Figaro, C. J. (1996). Crimes relativos ao abuso sexual. En C. Cohen, M. Segre \& F. C. Ferraz (Eds.), Saúde mental, crimes e justiça (pp.149-169). São Paulo: Edusp. 
Cohen, C. (2000). O incesto. En M. A. Azevedo \& V. N. A. Guerra (Eds.), Infância e violência doméstica: Fronteiras do conhecimento (pp. 211-225). São Paulo: Cortez.

Costa, L. F., Almeida, T. M. C., Ribeiro, M. A. \& Penso, M. A. (2009). Grupo Multifamiliar: espaço para a escuta das famílias em situação de abuso sexual. Psicologia em Estudo, 14(1), 21- 30.

Epston, D. (1997). "I am a bear": discovering discoveries. En C. Smith $\&$ D. Nylund (Eds.), Narrative therapy with children and adolescents (pp. 53-70). New York: Guilford Press.

Esber, K. M. (2009). Autores de violência sexual contra crianças e adolescentes. Goiânia: Cânone Editorial.

Faleiros, V. (2008). Parar o abuso e desenvolver a proteção. En L.F. Costa \& H. G. D. Lima (Eds.). Abuso sexual: a justiça interrompe a violência (pp. 159-170). Brasília: Liber Livros.

Foucault, M. (1978). Historia de la sexualidad (Vol.I). Madrid: Editorial Siglo XXI.

Furniss, T. (2002). Abuso sexual da criança: Uma abordagem multidisciplinar: Manejo, terapia e intervenção legal integrados a educação. Porto Alegre: Artmed.

Gergen, K. J. (1973). Social Psychology as History. Journal of Personality and Social Psychology. 26(2), 309-320.

Gergen, K. J. \& Gergen, M. (2010). Construcionismo social. Um convite ao diálogo. Rio de Janeiro: Instituto Noos.

Gergen, K. J. (1985).The social constructionist movement in modern psychology. American Psychologist, 40, 266-275.

Gergen, K. J. (1996). Realidades y relaciones: aproximación a la construcción social. Barcelona: Paidós.

Gergen, K. J. (1999). An invitation to social construction. London: Sage. Gergen, K. J. (2006). Construir la realidad. El futuro de la psicoterapia. Barcelona: Paidós.

Grandesso, M. (2000). Sobre a construção do significado. São Paulo: Casa do Psicólogo.

Grandesso, M. (2002). Terapias pós-modernas: um panorama. Sistemas Familiares, 18(3), 19-27. 
Grandesso, M. (2008). Desenvolvimento em terapia familiar: das teorias às práticas e das práticas às teorias. En L. C. Osório \& M. P. Valle (Eds.), Manual de terapia familiar (pp. 104-118). Porto Alegre: Artmed.

Habigzang, L. F. \& Caminha, R. M. (2004). Abuso sexual contra crianças e adolescentes: conceituação e intervenção clínica. São Paulo: Casa do Psicólogo.

Habigzang, L. F., Damásio, B. F. \& Koller, S. H. (2013). Impact evaluation of a cognitive hehavioral group therapy model in brazilian sexually abused girls. Journal of child sexual abuse, 22, 173-190.

Habigzang, L. F., Hatzemberg, R., Corte, F. D., Stroeher, F. \& Koller, S. H. (2009). Grupoterapia cognitivo-comportamental para criancas e adolescentes vítimas de abuso sexual. Revista de Saúde Pública, 43, 70-78.

Habigzang, L. F., Koller, S. H., Azevedo, G.A. \& Machado, X. P. (2005). Abuso sexual e dinâmica familiar: aspectos observados em processos jurídicos. Psicologia: Teoria e Pesquisa, 21(3), 341348.

Hoffman, L. (1993). Exchanging voices: A collaborative approach to family therapy. London: Karnac Books.

Hoffman, L. (2001). Family Therapy. New York: WWW Norton \& Company.

Ibañez, T. (1992). Cómo se puede no ser constructivista hoy en día? Revista de Psicoterapia, III(12), 17-27.

Leal, M. F. P. \& César, M. A. (Eds.) (2007). Indicadores de violência intrafamiliar e exploração sexual comercial de crianças e adolescentes (3 ed.). Brasília: CECRIA/Ministério da Justiça/CESE.

Lippert, T., Favre, T., Alexander, C. \& Cross, T. P. (2008). Families who begin versus decline therapy for children who are sexually abused. Child Abuse \& Neglect, 32, 859-868.

Omer, H. (1997). Intervençóes criticas em psicoterapia. Do impasse ao início da mudança. Porto Alegre: Artes Médicas. 
Omer, H. (2011). Nonviolent Resistance. A new approach to violent and self-destructive children. New York: Cambridge University Press. Trans. from Hebrew: Shoshana London Sappir and Haim Omer. Pakman, M. (2011). Palabras que permanecen, palavras por venir. Micropolitica y poética em psicoterapia. Barcelona: Gedisa Editorial.

Penso, A. M. \& Costa, L. F. (2008). A transmissão geracional em diferentes contextos da pesquisa à intervenção. São Paulo: Summus.

Penso, M. A., Conceição, M. I. G., Costa, L. F. \& Carreteiro, T. C. O. C. (2011). Jovens pedem socorro. O adolescente que praticou ato infracional e o adolescente que cometeu ofensa sexual. Brasília: Universa. Ponzio, A. (2010). Para uma filosofia do ato responsável. Sáo Carlos: Pedro e João editores.

Rasera, F.E., Guanes, C. \& Japur, M. (2004). Psicologia, ciência e construcionismo: dando sentido ao Self. Psicologia: Reflexão e Critica, 17(2),157-165.

Rasera, F.E. \& Japur, M. (2005). Os sentidos da construção social: o convite construcionista para a psicologia. Paidéia, 15(30), 21-29.

Rasera, E. F. \& Japur, M. (2007). Grupo como construção social: aproximaçóes entre construcionismo social e terapia de grupo. São Paulo: Vetor.

Sanderson, C. (2005). Abuso sexual em crianças. São Paulo: M. Books do Brasil.

Santos, S. S., Pelisoli, C. \& Dell'Aglio, D. D. (2012). Desvendando Segredos, padróes e dinâmicas familiares no abuso sexual. En L. F. Habigzang \& S. H. Koller (Eds.), Violência contra crianças e adolescentes. Teoria, pesquisa e prática. Porto Alegre: Artmed.

Santos, V. A., Costa, L. F. \& Silva, A. X. (2011). As medidas protetivas na perspectiva de famílias em situação de violência sexual. Psico, 42(1), 77-86.

Santos, V. A., Costa, L. F. \& Granjeiro, A. C. L. (2009). Intervenção no abuso sexual intrafamiliar: Ingerência invasiva ou proteçáo devida? Psico, 40(4), 515-523. 
Shotter, J. \& Lannamann, J. W. (2002). The situation of social constructionism. Theory and Psychology, 12(5), 577-609.

Shotter, J. (1993a). Conversational realities. Londres: Sage

Shotter, J. (1993b). Cultural politics of everyday life: social constructionism, rethoric and knowing of the third kind. Buckingham: Open University Press.

White, M. \& Epston, D. (1993). Medios narrativos para fines terapeuticos. Barcelona: Herder.

White, M. (1994). Guias para uma terapia familiar sistémica. Barcelona: Gedisa.

White, M. (2002). Reescribir la vida. Entrevistas y ensayos. Barcelona: Gedisa.

Recibido: 16 de marzo, 2014 Aceptado: 16 de abril, 2014 